\title{
SH2-Binding Motif
}

National Cancer Institute

\section{Source}

National Cancer Institute. SH2-Binding Motif. NCI Thesaurus. Code C14108.

Typically found in signaling proteins, the SH2-Binding Motif mediates regulated highaffinity physical interaction (binding) with the target SH2 (SRC Homology 2) domain. SH2 domains of $\sim 100$ amino acids bind to specific phosphotyrosine (pY)-containing motifs with dissociation constants of $\sim 50-500 \mathrm{nM}$. A conserved pocket of SH2 domains recognizes the $\mathrm{pY}$, and a more variable pocket binds residues C-terminal to $\mathrm{pY}$ that confer specificity. SH2 domains balance high affinity for $\mathrm{pY}$ and recognition of adjacent residues to allow specific discrimination. The $\mathrm{SH} 2$ domain, an anti-parallel b-sheet between a-helices, provides a positively charged b-sheet pocket for binding of pY moieties, and an extended b-sheet surface for binding residues C-terminal to pY. B-sheet surface differences have significant effects on ligand-specificity. ( $\mathrm{NCl})$ 